\title{
Türk Erkekleri Kozmetik Cerrahi Konusunda Ne Düşünüyor?
}

\author{
What Do Turkish Men Think About Cosmetic Surgery?
}

İzmir Bakırçay Üniversitesi Sağllk Bilimleri Fakültesi Hemşirelik Bölümü, İzmir, Türkiye

Correspondence:

Alive OKGÜN ALCAN

İzmir Bakırçay Üniversitesi Sağlık

Bilimleri Fakültesi Hemșirelik

Bölümü, İzmir, Türkiye

e-mail: aliyeokgun@gmail.com
Aliye Okgün Alcan, Nilay Canpolat

\section{Özet}

Bu çalışmanın amacı, Türk erkeklerinin kozmetik cerrahi konusundaki düşüncelerinin belirlenmesidir. Tanımlayıcı tipte olan bu çalışmanın verileri Mart-Nisan 2021 tarihleri arasında Kozmetik Cerrahiyi Kabul Ölçeği ile internet üzerinden toplanmıştır. Çalışmanın örneklemini, internet kullanabilen, çalışmaya katılmayı gönüllü olarak kabul eden, 18 yaş ve üzeri 228 erkek oluşturmuştur. Verilerin analizinde tanımlayııı istatistikler, Mann Whitney U Testi, Kruskal Wallis Testi ve Spearman korelasyon analizı kullanılmıştır. Bu araștırmada erkeklerin Kozmetik Cerrahi Kabul Ölçeği toplam puan, kișisel, sosyal ve düșünceler alt boyut puan ortalamalarının sırasıyla 50.88 \pm 21.64 (min:15 maks:105), 20.08 \pm 8.81 (min:5 maks:35), 13.49 \pm 7.63 (min:5 maks:35), 17.31 \pm 31 (min:5 maks:35) olduğu belirlenmiştir. Türk erkeklerinin yaşları (r:-0141 p:0.033) ve kendi görünüşlerinden memnuniyet düzeyleri (r:-0.150 p:0.023) ile Kozmetik Cerrahi Kabul Ölçeği toplam puanı arasında negatif yönde zayıf ilişki olduğu saptanmıștır. Kozmetik cerrahi geçirmek isteyen erkeklerin kozmetik cerrahiye yönelik tutumlarının daha olumlu olduğu saptanmıştır (U:2381.00 p:0.0001). Sonuç olarak, Türk erkeklerinin kozmetik cerrahiye ilişkin tutumlarının yaş, kendi görünüşlerinden memnuniyet düzeyleri ve gelecekte kozmetik cerrahi geçirmek isteme durumlarından etkilendiği belirlenmiştir.

Anahtar Kelimeler: Kozmetik cerrahi, erkek, düșünce

\section{Abstract}

The aim of this study is to determine Turkish men's opinions on cosmetic surgery. The data of this descriptive study were collected over the internet using the Cosmetic Surgery Acceptance Scale between March-April 2021. The sample of the study consisted of 228 men aged 18 and over who can use the internet and voluntarily agree to participate in the study. Descriptive statistics, Mann Whitney U Test, Kruskal Wallis Test and Spearman correlation analysis were used to analyze the data. In this study, men's Cosmetic Surgery Acceptance Scale total score, personal, social, and thoughts sub-dimension mean scores were respectively $50.88 \pm 21.64$ (min: 15 max: 105), $20.08 \pm 8.81$ (min: 5 max: 35), $13.49 \pm 7.63$ (min: 5 max: 35), $17.31 \pm 31$ (min: 5 max: 35). A weak negative correlation was found between the ages of Turkish men ( $\mathrm{r}:-0141 \mathrm{p}: 0.033)$ and their level of satisfaction with their appearance (r: $-0.150 \mathrm{p:} \mathrm{0.023)} \mathrm{and} \mathrm{the} \mathrm{total} \mathrm{score} \mathrm{of} \mathrm{the} \mathrm{Cosmetic} \mathrm{Surgery} \mathrm{Acceptance} \mathrm{Scale.} \mathrm{In} \mathrm{conclusion,} \mathrm{it} \mathrm{was} \mathrm{determined} \mathrm{that} \mathrm{Turkish} \mathrm{men's}$ attitudes towards cosmetic surgery are affected by age, level of satisfaction with their appearance, and their willingness to undergo cosmetic surgery in the future.

Keywords: Cosmetic surgery, man, opinion 


\section{Giriş}

Son y1llarda teknoloji ve kozmetik cerrahide meydana gelen gelişmelere paralel olarak ameliyat sonrası sürecin daha az ağrılı, acısız ve komplikasyonsuz olması mümkün kılınmıştır. Bununla birlikte geçmişte çok maliyetli olan kozmetik cerrahi ameliyatları günümüzde farklı sosyoekonomik düzeydeki bireylerin rahatlıkla başvurabildiği müdahaleler haline gelmiştir $(1,2)$. Modern insanın kendisini sürekli güzelleştirmeye çalışması ve güzelliği elde etmek için her yola başvurması kozmetik cerrahiyi gün geçtikçe daha çekici bir seçeneğe dönüştürmektedir. Tüm bu nedenlerle kozmetik cerrahiye başvuran bireylerin sayısı çarpıcı bir şekilde artarak kozmetik cerrahi artık bir "yaşam tarzı" haline gelmiştir (3). Uluslararası Estetik Plastik Cerrahi Derneği'nin (International Society of Aesthetic Plastic Surgery) verilerine göre 2019 yllında estetik amaçlı $11,363,569$ cerrahi ve $13,618,735$ cerrahi olmayan işlem gerçekleştirilmiştir. Aynı raporda ülkemizde 2019 yılında 351,930 cerrahi ve 402,462 cerrahi olmayan olmak üzere toplam 754,392 estetik amaçlı işlem gerçekleştirildiği belirtilmektedir (2).

Beden imajına ilişkin olumsuz düşüncelere sahip olan kişiler bu durumla baş edebilmek için bazı yöntemler arayışı içine girmektedirler. $\mathrm{Bu}$ yöntemlerden bir tanesi kozmetik cerrahidir (3). İnsanları kozmetik cerrahi konusunda motive eden en önemli faktörün "bir bireyin bedenine atfettiği bir dizi alg1, duygulanım ve fikir olarak tanımlanan beden imajından duyulan memnuniyetsizlik" olduğu bilinmektedir $(4,5)$. Kadınların ideal fiziksel görünüme ulaşmak için daha fazla sosyokültürel baskı yaşadıklarından kozmetik cerrahiyi düşünmeye daha yatkın olduklarına inanılmaktadır $(3,6)$. Buna karşın günümüzde erkeklerin de beden imajlarından duydukları memnuniyetsizlik nedeniyle kozmetik cerrahiye başvuru oranlarının arttı̆̆ bilinmektedir $(3,7)$. Erkeklerin en çok tercih ettiği yöntemler arasında rinoplasti, redüksiyon mamoplasti, liposuction, otoplasti gibi işlemler yer almaktadır (2).

Kozmetik cerrahi ile kişilerin beden imajını düzelterek memnuniyet ve psikolojik durumunda iyileşme sağlamak amaçlansa da kozmetik cerrahi kronik ağrı, anksiyete, depresyon, düşük benlik saygısı ve cerrahi sonrasi psikolojik rahatsılılk gibi olumsuz sonuçlara neden olabilmektedir $(7,8)$. Bununla birlikte erkeklerin kadınlara göre kozmetik cerrahi sonrası olumsuz psikososyal problemler yaşadıkları bilinmektedir (7). Bu nedenle erkekleri kozmetik cerrahi olmaya karar verme konusunda motive eden faktörlerin belirlenmesi, ameliyata yüklenen anlamın tanınması daha iyi estetik ve psikolojik sonuçlar için son derece önemlidir $(6,7,9)$. Erkeklerde kozmetik prosedürlerin sayısı kadınlara göre daha az olmasina rağmen, mevcut eğilim popülaritesinin artmaya devam edeceği yönündedir (10). Kozmetik cerrahi konusunda kadınlarla yapılmış birçok çalışma bulunsa da erkeklerin kozmetik cerrahiye yönelik düşüncelerini inceleyen çalışma sayısı oldukça sınırlıdır (7). $\mathrm{Bu}$ nedenle bu çalışma Türk erkeklerinin kozmetik cerrahi konusundaki düşüncelerinin belirlenmesi amacıyla yürütülmüştür.

\section{Gereç ve Yöntemler}

Tanımlayıcı tipteki bu çalışmanın örneklemini 3 Şubat - 14 Nisan 2021 tarihleri arasında aktif olarak internet kullanabilen, araştırmaya katılmayı gönüllü olarak kabul eden, 18 yaş ve üzeri 228 erkek oluşturmuştur. Türkiye İstatistik Kurumu verilerine göre Türkiye'deki erkek nüfus 41 milyon 721 bin 136 kişidir. Bu doğrultuda

http://sampsize.sourceforge.net/iface/

adresinde yer alan evreni bilenen grubun örneklem hesabı uygulaması ile $\% 5$ hata pay1 ve erkeklerde estetik cerrahi uygulanma oran $\% 13$ olarak ele alındığında çalışmanın örneklem sayısı 174 olarak belirlenmiştir (11).

$\mathrm{Bu}$ çalışmanın verileri 3 Şubat - 16 Nisan 2021 tarihleri arasında internet üzerinden toplanmıştır. Çalışmanın yürütülebilmesi için etik izin alındıktan sonra veri toplama araçları elektronik ortamda yayımlanmıştır. Çalışmanın bağlantısını içeren davet mektubu katılımcılara sosyal paylaşım siteleri üzerinden gönderilmiştir.

$\mathrm{Bu}$ araştırmanın verileri "Veri Toplama Formu" ve "Kozmetik Cerrahiyi Kabul 
Ölçeği” kullanılarak toplanmıştır. Veri Toplama Formu'nda araştırma kapsamına alınan bireylerin sosyo-demografik özellikleri ve kozmetik cerrahi konusundaki deneyimlerini belirlemeyi amaçlayan sorular yer almaktadır. Henderson-King (2005) tarafindan geliştirilen Kozmetik Cerrahiyi Kabul Ölçeği (KCKÖ); bireylerin kozmetik cerrahiye ilişkin tutumlarını belirlemeyi amaçlayan 7'li likert tipte 15 maddelik bir ölçektir. Ölçeğin kişisel, sosyal ve düşünceler olmak üzere üç alt boyutu bulunmaktadır. KCKÖ'nden en az 15, en fazla 105 puan alınabilmektedir. Alt boyutlar ve ölçek toplam puanının yükselmesi kozmetik cerrahiye ilişkin tutumların olumlu olduğunu gösterir. Ölçeğin orijinal versiyonunun Cronbach alfa katsayıs1 0.91-0.93 arasinda olduğu bildirilmiştir. Ölçeğin Türkçe versiyonunun Cronbach alfa 0.92 olduğu belirtilmiştir (12). $\mathrm{Bu}$ çalışmada ölçeğin Cronbach Alpha katsayısı 0.93 olarak hesaplanmıştır.

Araştırmanın yürütülebilmesi için İzmir ilinde yer alan bir üniversitenin girişimsel olmayan klinik araştırmalar etik kurulundan yazılı izin alınmıştır (Karar no: 154 Tarih: 29.01.2021). Veri toplama formlarının giriş bölümünde çalışmanın amacı ve uygulaması ile ilgili gerekli açıklamalara yer verilmiştir. $\mathrm{Bu}$ bilgiler doğrultusunda veri toplama formunun giriş bölümünde "Çalışmaya katılmayı kabul ediyorum" ve "Çalışmaya katılmayı kabul etmiyorum" seçenekleri yer almıştır. $\mathrm{Bu}$ doğrultuda çalışmaya katılmayı kabul eden kat1lımcilar veri toplama formunu doldurmaya geçebilmiştir. Araştırmada kullanılan KCKÖ’nin uygulanabilmesi için ölçeğin
Türkçe geçerlilik ve güvenilirlik çalışmasını yapan yazarlardan e-posta yoluyla yazılı olarak izin alınmıştır.

\section{Ístatistiksel analiz}

Araştırmadan elde edilen veriler Statistical Package for the Social Sciences (SPSS) for Windows 20.0 paket programı kullanılarak analiz edilmiştir. Verilerin değerlendirilmesinde tanımlayıcı istatistikler (say1, yüzde, ortalama, standart sapma) kullanılmıştır. Verilerin normal dağılım gösterip göstermediğini belirlemek için Kolmogorov Smirnov Testi uygulanmıştır. Parametrik olmayan veriler için Mann Whitney U Testi, Kruskal Wallis Testi ve Spearman korelasyon analizi uygulanmıştır. Tüm sonuçlarda 0.05 'ten küçük olan $p$ değerleri istatistiksel olarak anlamlı kabul edilmiştir $(\mathrm{p}<0.05)$.

\section{Bulgular}

Bu çalışmada katılımcıların yaş ortalamasının 24.55 \pm 7.91 (min: 18 maks:60) yaş; beden kitle indeksi ortalamasının $24.33 \pm 4.09 \mathrm{~kg} / \mathrm{m}^{2}$ (min:17.36 maks:41.51) olduğu belirlenmiştir. Araştırma kapsamına alınan katılımcıların sosyo-demografik özelliklerine göre dağılımı Tablo 1'de verilmiştir.

$\mathrm{Bu}$ çalışmada erkeklerin kendi görünüşlerinden memnuniyet düzeyi puan ortalamalarının 10 üzerinden $\quad 6.84 \pm 2.16$ (min:0 maks:10) olduğu görülmüsşür. Türk erkeklerinin kozmetik cerrahi konusundaki düşüncelerine göre dağılımı Tablo 2'de belirtilmiştir.

Tablo 1. Katılımcıların sosyo-demografik özelliklerine göre dağılımları

\begin{tabular}{lcc}
\hline Sosyo-Demografik Özellikler & Sayı & Yüzde \\
\hline Medeni durum & 37 & 16.2 \\
Evli & 191 & 83.8 \\
Bekar & 151 & 66.2 \\
Eğitim durumu & 65 & 28.5 \\
Lise & 12 & 5.3 \\
Üniversite & & \\
Lisansüstüi & 14 & 6.1 \\
Yaşadığı bölge & 16 & 7.0 \\
Doğu Anadolu & 19 & 8.3 \\
Karadeniz & 25 & 11.0 \\
Akdeniz & 28 & 12.3 \\
Güneydoğu Anadolu & & \\
İç Anadolu & & \\
\hline
\end{tabular}




\begin{tabular}{lcc}
\hline Marmara & 28 & 12.3 \\
Ege & 98 & 43.0 \\
Çalışma durumu & & \\
Çalışan & 96 & 42.1 \\
Çalışmayan & 132 & 57.9 \\
Son beş yıl içinde kilo kaybı & & \\
Olan & 72 & 31.6 \\
Olmayan & 156 & 68.4 \\
\hline
\end{tabular}

Tablo 2. Erkeklerin kozmetik cerrahi konusundaki düşüncelerine göre dağılımı

\begin{tabular}{|c|c|c|}
\hline Değişken & Sayı & Yüzde \\
\hline \multicolumn{3}{|l|}{ Kozmetik amaçlı işlem geçirme durumu } \\
\hline Geçiren & 11 & 4.8 \\
\hline Geçirmeyen & 217 & 95.2 \\
\hline \multicolumn{3}{|l|}{ Kozmetik amaçlı işlem geçirmeme nedeni* } \\
\hline Kozmetik cerrahinin sadece kadınlar için olduğunu düşünen & 2 & 0.9 \\
\hline Aile/partneri istemeyen & 4 & 1.8 \\
\hline Günah olduğunu düşünen & 9 & 3.9 \\
\hline Türk toplumunun kültürel yapısı & 11 & 4.8 \\
\hline Ameliyat korkusu & 18 & 7.9 \\
\hline Maddi yetersizlik & 39 & 17.1 \\
\hline Görünüşünden memnun olan & 170 & 74.6 \\
\hline \multicolumn{3}{|l|}{ Kozmetik cerrahi/işlem geçirmek isteme durumu } \\
\hline İsteyen & 112 & 49.1 \\
\hline İstemeyen & 116 & 50.9 \\
\hline \multicolumn{3}{|l|}{ Kozmetik cerrahi/işlem geçirmek istediği bölge* } \\
\hline Saç ekimi & 2 & 0.9 \\
\hline Yara izi & 3 & 1.3 \\
\hline Bacak & 3 & 1.3 \\
\hline Göz kapağı & 3 & 1.3 \\
\hline Dudak & 3 & 1.3 \\
\hline Kulak & 4 & 1.8 \\
\hline Meme küçültme & 5 & 2.2 \\
\hline Kalça & 5 & 2.2 \\
\hline Kaş & 7 & 3.1 \\
\hline Çene & 7 & 3.1 \\
\hline Karın & 15 & 6.6 \\
\hline Burun & 78 & 34.2 \\
\hline
\end{tabular}

$\mathrm{Bu}$ araştırmada erkeklerin KCKÖ toplam puan ortalamasinın $50.88 \pm 21.64$ (min:15 maks:105) olduğu saptanmıştır. Ölçeğin alt boyutları olan kişisel, sosyal ve düşünceler puan ortalamalarının sirasiyla $20.08 \pm 8.81$ (min:5 maks:35), $13.49 \pm 7.63 \quad$ (min:5 maks:35), 17.31 \pm 31 (min:5 maks:35) olduğu belirlenmiştir.

Türk erkeklerinin yaşları ile KCKÖ toplam puanı (r:-0141 p:0.033) ve düşünceler alt boyutu (r:-0.162 p:0.014) arasinda negatif 
yönde zayıf ilişki olduğu saptanmıştır. Katılımcıların yaşları ile KCKÖ kişisel (r:$0.119 \mathrm{p}: 0.073$ ) ve sosyal (r:-0.079 p:0.235) alt boyutları arasında negatif yönde ilişki olduğu ancak bu ilişkinin istatistiksel olarak anlamlı olmadığ1 görülmüştür. Katılımcıların beden kitle indeksi ile KCKÖ toplam puanı (r:-0.082 p:0.219), kişisel alt boyut (r:-0.089 p:0.182), sosyal alt boyut (r:-0.019 p:0.780) ve düşünceler alt boyutu (r:-0.086 p:0.196) arasındaki ilişkinin istatistiksel olarak anlamlı olmadığ1 saptanmıştır. Türk erkeklerinin kendi görünüşlerinden memnuniyet düzeyleri ile KCKÖ toplam puanı (r:-0.150 p:0.023), sosyal alt boyut (r:-0.166 p:0.012) ve düşünceler alt boyutu (r:-0.185 p:0.005) arasında negatif yönde anlamlı ilişki olduğu saptanmıştır. Katılımcıların kendi görünüşlerinden memnuniyet düzeyleri ile KCKÖ sosyal alt boyutu arasındaki ilişkinin anlamlı olmadığ 1 belirlenmiştir (r:-0.082 p:0.219). Araştırma kapsamına dahil edilen erkeklerin değişkenlere göre kozmetik cerrahi kabul ölçeği puan ortalamalarının dağılımı Tablo 3'de belirtilmiştir.

Tablo 3. Değişkenlere göre kozmetik cerrahi kabul ölçeği puan ortalamalarının dağılımı

\begin{tabular}{|c|c|c|c|c|}
\hline Değişken & $\begin{array}{c}\text { KCKÖ } \\
\text { Ort } \pm \text { SS }\end{array}$ & $\begin{array}{c}\text { Kişisel } \\
\text { Ort } \pm \text { SS } \\
\end{array}$ & $\begin{array}{c}\text { Sosyal } \\
\text { Ort } \pm \text { SS }\end{array}$ & $\begin{array}{c}\text { Düşünceler } \\
\text { Ort } \pm \text { SS }\end{array}$ \\
\hline $\begin{array}{l}\text { Medeni durum } \\
\text { Evli } \\
\text { Bekar }\end{array}$ & $\begin{array}{c}50.14 \pm 21.58 \\
51.02 \pm 21.70 \\
\mathrm{U}: 3434.50 \\
\mathrm{p}: 0.787\end{array}$ & $\begin{array}{c}20.46 \pm 9.08 \\
20.01 \pm 8.77 \\
\mathrm{U}: 3472.50 \\
\text { p: } 0.868\end{array}$ & $\begin{array}{c}13.46 \pm 7.37 \\
13.49 \pm 7.69 \\
\mathrm{U}: 3429.50 \\
\text { p: } 0.776\end{array}$ & $\begin{array}{c}16.22 \pm 8.04 \\
17.52 \pm 8.40 \\
\mathrm{U}: 3235.00 \\
\text { p: } 0.416\end{array}$ \\
\hline $\begin{array}{l}\text { Eğitim durumu } \\
\text { Lise } \\
\text { Üniversite } \\
\text { Lisansüstü }\end{array}$ & $\begin{array}{c}52.20 \pm 21.70 \\
48.05 \pm 21.77 \\
49.58 \pm 20.25 \\
\mathrm{X}^{2}: 1.80 \mathrm{p}: 0.407\end{array}$ & $\begin{array}{c}20.46 \pm 8.63 \\
19.37 \pm 9.47 \\
19.25 \pm 7.58 \\
\mathrm{X}^{2}: 0.96 \mathrm{p}: 0.619\end{array}$ & $\begin{array}{c}13.82 \pm 7.81 \\
12.65 \pm 7.29 \\
13.83 \pm 7.35 \\
\mathrm{X}^{2}: 1.14 \mathrm{p}: 0.564\end{array}$ & $\begin{array}{c}17.92 \pm 8.45 \\
16.03 \pm 8.17 \\
16.50 \pm 7.60 \\
\mathrm{X}^{2}: 2.51 \mathrm{p}: 0.284\end{array}$ \\
\hline $\begin{array}{l}\text { Yaşadığı bölge } \\
\text { Doğu Anadolu } \\
\text { Karadeniz } \\
\text { Akdeniz } \\
\text { Güneydoğu Anadolu } \\
\text { İç Anadolu } \\
\text { Marmara } \\
\text { Ege }\end{array}$ & $\begin{array}{c}51.93 \pm 20.96 \\
58.81 \pm 25.40 \\
51.16 \pm 23.82 \\
55.44 \pm 18.30 \\
51.57 \pm 20.99 \\
45.50 \pm 19.00 \\
49.55 \pm 22.35 \\
X^{2}: 5.53 \mathrm{p}: 0.478\end{array}$ & $\begin{array}{c}19.86 \pm 8.22 \\
22.81 \pm 9.20 \\
18.63 \pm 8.72 \\
21.48 \pm 7.15 \\
20.39 \pm 8.60 \\
18.36 \pm 9.22 \\
20.00 \pm 9.23 \\
\mathrm{X}^{2}: 3.82 \mathrm{p}: 0.702\end{array}$ & $\begin{array}{c}13.64 \pm 8.27 \\
15.50 \pm 7.64 \\
13.63 \pm 9.73 \\
14.76 \pm 6.55 \\
13.39 \pm 7.13 \\
11.14 \pm 6.70 \\
13.48 \pm 7.77 \\
X^{2}: 6.15 \mathrm{p}: 0.407\end{array}$ & $\begin{array}{c}18.43 \pm 7.78 \\
20.50 \pm 10.18 \\
18.89 \pm 8.60 \\
19.20 \pm 8.99 \\
17.79 \pm 8.69 \\
16.00 \pm 7.33 \\
16.07 \pm 7.97 \\
\mathrm{X}^{2}: 6.30 \mathrm{p}: 0.390\end{array}$ \\
\hline $\begin{array}{l}\text { Çalışma durumu } \\
\text { Çalışan } \\
\text { Çalışmayan }\end{array}$ & $\begin{array}{c}48.49 \pm 21.93 \\
52.61 \pm 21.33 \\
U: 5609.00 \\
\text { p: } 0.139\end{array}$ & $\begin{array}{c}19.02 \pm 9.23 \\
20.86 \pm 8.43 \\
\mathrm{U}: 5547.50 \\
\text { p: } 0.109\end{array}$ & $\begin{array}{c}13.16 \pm 7.80 \\
13.73 \pm 7.52 \\
\mathrm{U}: 5961.00 \\
\text { p: } 0.444\end{array}$ & $\begin{array}{l}16.31 \pm 8.00 \\
18.03 \pm 8.54 \\
\mathrm{U}: 5581.50 \\
\mathrm{p}: 0.125\end{array}$ \\
\hline $\begin{array}{l}\text { Son beş yıl içinde kilo kaybı } \\
\text { Olan } \\
\text { Olmayan }\end{array}$ & $\begin{array}{c}52.31 \pm 22.66 \\
50.22 \pm 21.19 \\
U: 5374.00 \\
\text { p: } 0.601\end{array}$ & $\begin{array}{c}19.83 \pm 8.54 \\
20.20 \pm 8.95 \\
\text { U: } 5510.50 \\
\text { p: } 0.820\end{array}$ & $\begin{array}{c}14.56 \pm 8.51 \\
12.99 \pm 7.16 \\
\text { U: } 5130.50 \\
\text { p: } 0.293\end{array}$ & $\begin{array}{c}17.92 \pm 8.79 \\
17.03 \pm 8.14 \\
\text { U: } 5273.00 \\
\text { p: } 0.458\end{array}$ \\
\hline $\begin{array}{l}\text { Kozmetik amaçlı işlem geçirme } \\
\text { durumu } \\
\text { Geçiren } \\
\text { Geçirmeyen }\end{array}$ & $\begin{array}{c}62.09 \pm 19.71 \\
50.31 \pm 21.62 \\
\mathrm{U}: 803.00 \\
\mathrm{p}: 0.067\end{array}$ & $\begin{array}{c}23.00 \pm 7.27 \\
19.94 \pm 8.87 \\
\mathrm{U}: 978.00 \\
\text { p: } 0.312\end{array}$ & $\begin{array}{c}16.82 \pm 8.23 \\
13.32 \pm 7.58 \\
\mathrm{U}: 890.50 \\
\text { p: } 0.154\end{array}$ & $\begin{array}{c}22.27 \pm 7.72 \\
17.06 \pm 8.31 \\
U: 745.00 \\
\text { p:0.035 }\end{array}$ \\
\hline $\begin{array}{l}\text { Kozmetik cerrahi/işlem geçirmek } \\
\text { isteme durumu } \\
\text { İsteyen } \\
\text { İstemeyen }\end{array}$ & $\begin{array}{c}62.84 \pm 19.98 \\
39.33 \pm 16.27 \\
U: 2381.00 \\
\text { p:0.0001 }\end{array}$ & $\begin{array}{c}23.29 \pm 8.04 \\
16.99 \pm 8.43 \\
\mathrm{U}: 3889.00 \\
\text { p:0.0001 }\end{array}$ & $\begin{array}{c}16.80 \pm 7.50 \\
10.28 \pm 6.28 \\
\text { U:3053.00 } \\
\text { p:0.0001 }\end{array}$ & $\begin{array}{c}22.75 \pm 7.31 \\
12.05 \pm 5.38 \\
U: 1604.50 \\
\text { p:0.0001 }\end{array}$ \\
\hline
\end{tabular}




\section{Tartışma ve Sonuç}

Kozmetik cerrahi kadınlar arasında daha çok tercih edilmesinin yanında günümüzde erkekler arasında da hizla popülerlik kazanan işlemler arasında yer almaktadır $(3,10,13)$. Amerikan Plastik Cerrahlar Derneği (American Society of Plastic Surgeons) 2019 yılında gerçekleştirilen kozmetik cerrahi işlemlerinin \%13'ünün erkeklere uygulandığını belirtmiştir (11). Park ve arkadaşları tarafından yürütülen bir çalışmada erkeklerin \%14.8'i geçmişte kozmetik işlem geçirdiği; kozmetik cerrahi deneyimi olmayan erkeklerin yaklaşı \%40'ının ileride işlem yaptırmayı planladıkları belirtilmiştir (14). Koreli üniversite öğrencileri ile yürütülen bir çalışmada erkek öğrencilerin \%15.7'sinin kozmetik cerrahi deneyimi olduğu ve \%36.9'unun kozmetik cerrahi geçirmeyi istedikleri belirtilmiştir (15). Bu çalışmada erkeklerin $\% 4.8$ 'i geçmişte kozmetik cerrahi geçirdiğini belirtmiştir. Bunun yanında ilginç bir şekilde, katılımcıların neredeyse yarısı kozmetik amaçlı işlem yaptırmayı istediklerini belirtmiştir. Çalışmamızda Türk erkeklerinin kozmetik cerrahi geçirme oranları literatürde belirtilen oranlardan düşük bulunmuştur. Bununla birlikte Türk erkeklerinin kozmetik cerrahi geçirme isteğinin benzer çalışmalardan yükssek olduğu saptanmıştır. $\mathrm{Bu}$ doğrultuda Türk erkeklerinin kozmetik cerrahi geçirme oranları düşük olsa da gelecekte ameliyat olmayı düşünenlerin oranları göz önünde bulundurulduğunda kozmetik cerrahinin erkekler arasında daha çok tercih edileceği ve popülaritesinin artacă̆ 1 söylenebilir.

Kim ve arkadaşları erkek üniversite öğrencilerinin KCKÖ toplam puan ortalamasinın $\quad 52.27 \pm 16.78$ olduğunu belirtmişlerdir (16). Seo ve Kim tarafindan yürütülen bir çalışmada erkek katılımcıların KCKÖ toplam puan ortalamasinın $62.47 \pm 18.52$ olduğu belirtilmiştir (15). Bu araştırmada erkeklerin KCKÖ toplam puan ortalamasinin $\quad 50.88 \pm 21.64 \quad$ olduğu saptanmıştır. Bulgularımızın benzer çalışmaların sonuçlarından düşük olduğu saptanmıştır. Bu farklılığın Türk toplumunun kültürel yapısından kaynaklanabileceği düşünülmektedir. $\mathrm{Bu}$ doğrultuda kozmetik cerrahiyi kabule kültürel faktörlerin etkisinin incelendiği çalışmalara gereksinim olduğu söylenebilir.

$\mathrm{Bu}$ çalışmada kozmetik cerrahi geçirmek istediğini belirten erkeklerin çoğunun rinoplasti başta olmak üzere yüz görünümünü değiştirecek işlemler üzerine odaklandığ 1 saptanmıştır. Uluslararası Estetik Plastik Cerrahi Derneği'nin (International Society of Aesthetic Plastic Surgery) verilerine göre rinoplastinin 2019 yılında erkekler tarafindan en çok tercih edilen kozmetik cerrahi yöntemlerinden biri olduğu rapor edilmiştir (2). Brown ve arkadaşları tarafindan yapılan bir çalışmada erkeklerin kozmetik cerrahi işlemler arasında en çok rinoplastiyi tercih ettikleri belirtilmiştir (6). İngiliz ve Çinli erkekler arasında en popüler olan kozmetik cerrahi işlemlerinin rinoplasti, blefaroplasti ve bişektomi gibi yüz görünümüne odaklanan ameliyatlar olduğu belirtilmektedir $(3,10)$. Bulgularımız literatüre benzerlik göstermektedir.

Amerika, İngiltere ve Güney Kore'de yürütülen çalışmalarda yaşın kozmetik cerrahiyi kabul etme üzerinde etkili olan bir faktör olduğu belirtilmiştir $(6,15,17)$. Çin'de yapılan kozmetik cerrahi işlemlerinin büyük bölümünün lise ve üniversite öğrencilerine uygulandığ 1 belirtilmektedir (3). $\mathrm{Wu}$ ve arkadaşları tarafından yürütülen bir çalışmada erkeklerde yaşla kozmetik cerrahiyi kabul arasında iliş̧i olduğu belirtilmiştir (8). Swami ve arkadaşları yaş ile kozmetik cerrahiyi kabul arasında negatif yönde ilişki olduğunu belirtmiştir (13). Bu çalışmada da Türk erkeklerinin yaşları ile KCKÖ toplam puanı (r:-0141 p:0.033) ve düşünceler alt boyutu (r:$0.162 \mathrm{p}: 0.014)$ arasinda negatif yönde zayif ilişki olduğu saptanmıştır. Bir başka ifadeyle Türk erkeklerinin yaşları ilerledikçe kozmetik cerrahiyi kabul etmeye ilişkin tutumları olumsuz etkilenmektedir. Bu sonuçların daha genç yaşlarda diş görünüşe daha çok önem verilmesinden düşünülmektedir.

kaynaklandığ

$\mathrm{Bu}$ çalışmada beklenenin aksine beden kitle indeksi arttıkça kozmetik cerrahiyi karar verme tutumlarının azaldığı ancak bu iliş̧inin 
anlamlı olmadığ 1 belirlenmiştir. Matera ve arkadaşları tarafindan yapılan çalışmada da vücut yağından duyulan memnuniyetsizliğin kozmetik cerrahiye daha az ilgi duyulmasıla ilişkili olduğu belirtilmiştir (7). Bu durumun BKİ yüksek olan kişilerin diş görünüşlerine önem vermiyor olabileceğinden kaynaklandığg 1 düșünülmektedir.

Literatürde dış görünüşlerinden memnun olmayan bireylerin kozmetik cerrahiye daha sık başvurdukları belirtilmektedir $(3,7,17)$. Park ve arkadaşları tarafından yapılan bir çalışmada dış görüşten memnuniyetsizliğin kozmetik cerrahiye başvurmada en önemli etken olduğu belirtilmiştir (14). Bu durum sadece kadınlar için geçerli olmamaktadır. Dış görünüşünden memnuniyetsizliğin erkeklerin kozmetik cerrahi geçirme isteği ile önemli ölçüde ilişkili olduğu belirtilmektedir $(6,7,18)$. İngiliz erkeklerle yürütülen bir çalışmada kendini çekici görme puanının düşük olmasının ameliyat olma olasılığını arttırdığ 1 belirtilmiștir (6). Amerikalı erkeklerle yürütülen benzer bir çalışmada da erkeklerin vücut memnuniyetsizliğinin kozmetik cerrahiye karşı daha olumlu tutumlarla önemli ölçüde ilișkili olduğu saptanmıștır (18). Bu çalışmada da Türk erkeklerinin dış görünüşünden memnun olma düzeyi azaldıkça kozmetik cerrahiye ilişkin tutumlarının daha olumlu olduğu belirlenmiştir. $\mathrm{Bu}$ sonucun

\section{KAYNAKLAR}

1. Dean NR, Foley K, Ward P. Defining cosmetic surgery. Australas J Plast Surg. 2018;1:95-103.

2. ISAPS. ISAPS International Survey on Aesthetic/ Cosmetic Procedures Performed in 2019 [Internet]. [cited 2020 Dec 31]. Available from: https://www.isaps.org/wpcontent/uploads/2020/12/Global-Survey-2019.pdf

3. Wang Y, Chu X, Nie J, Gu X, Lei L. Selfieediting, facial dissatisfaction, and cosmetic surgery consideration among Chinese adolescents: A longitudinal study. Curr Psychol. 2021;

4. Mattei V, Bagliacca E, Ambrosi A, Lanfranchi L, Preis F, Sarno L. The Impact of Cosmetic Plastic Surgery on Body Image and Psychological WellBeing: A Preliminary Study. Int J Psychol Behav Anal. 2015;1:103.

5. Mattei VE Di, Bagliacca EP, Lavezzari L, Pierro R Di, Carnelli L, Zucchi P, et al. Body Image and Personality in Aesthetic Plastic Surgery: A Case- kendini toplumsal çekicilik idealleri seviyesinin altında hisseden kişilerin dış görünüşlerinden memnuniyetsizlik duymalarına ve muhtemelen kozmetik cerrahiye başvurmayı düşünmeye yol açtı̆̆ını göstermektedir.

Seo ve Kim tarafindan yürütülen bir çalışmada kozmetik cerrahi geçirmeyi planlayanların KCKÖ toplam puan ortalamasının kozmetik cerrahi geçirmeyi planlamayanlardan daha yüksek olduğu belirtilmiştir (15). Bu çalışmada da Seo ve Kim'in çalışmasına benzer şekilde kozmetik cerrahi geçirmek isteyenlerin kozmetik cerrahiye yönelik tutumlarının daha olumlu olduğu saptanmıştır. $\mathrm{Bu}$ beklenen bir sonuçtur.

$\mathrm{Bu}$ çalışma sonucunda Türk erkeklerinin yaklaşık olarak yarısının gelecekte kozmetik cerrahi geçirmeyi planladığı belirlenmiştir. Erkeklerin kozmetik cerrahiye ilişkin tutumlarının yaş, kendi görünüşlerinden memnuniyet düzeyleri ve gelecekte kozmetik cerrahi geçirmek isteme durumlarından etkilendiği belirlenmiştir. Genç erkeklerin estetik cerrahiye ilişkin tutumlarını etkileyen sosyokültürel faktörlerin incelendiği çalışmaların planlanması ayrıca genç erkeklere yönelik pozitif beden algısının geliştirilmesine yönelik eğitim programlarının arttırılması önerilmektedir.
Control Study. Open J Med Psychol. 2015;04:3544.

6. Brown A, Furnham A, Glanville L, Swami V. Factors that affect the likelihood of undergoing cosmetic surgery. Aesthetic Surg J. 2007;27:5018.

7. Matera C, Nerini A, Stefanile C. Why are men interested in cosmetic surgery procedures? Examining the role of different forms of peer influence, social comparison, internalization, and body dissatisfaction. Body Image [Internet]. 2018;26:74-7.

8. Wu Y, Alleva JM, Mulkens S. Factor Analysis and Psychometric Properties of the Chinese Translation of the Acceptance of Cosmetic Surgery Scale. Body Image. 2020;33:244-56.

9. Alotaibi AS. Demographic and cultural differences in the acceptance and pursuit of cosmetic surgery: a systematic literature review. 
PRS Glob Open. 2021;9:e3501.

10. Kain N, Amar O. Cosmetic surgery in men. Trends Urol Men's Heal. 2020;11:22-6.

11. American Society of Plastic Surgeons. 2019 Plastic Surgery Statistics [Internet]. 2019. Available from: https://www.plasticsurgery.org/documents/News/S tatistics/2019/cosmetic-procedures-men-2019.pdf

12. Karaca S, Karakoc A, Onan N, Kadıŏlu H. Validity and reliability of the Turkish version of the acceptance of cosmetic surgery scale (ACSS). J Psychiatr Nurs. 2017;8:17-22.

13. Swami V, Chamorro-Premuzic $\mathrm{T}$, Bridges $\mathrm{S}$, Furnham A. Acceptance of cosmetic surgery: Personality and individual difference predictors. Body Image. 2009;6:7-13.

14. Park RH, Myers PL, Langstein HN. Beliefs and trends of aesthetic surgery in south korean young adults. Arch Plast Surg. 2019;46:612-6.

15. 15. Seo YA, Kim YA. Factors Affecting Acceptance of Cosmetic Surgery in Adults in Their 20s-30s. Aesthetic Plast Surg [Internet]. 2020;44:1881-8.

16. Kim Y, Chae D, Kim H. Factors affecting acceptance of cosmetic surgery among undergraduate students. J Korea Contents Assoc. 2017;17:455-64.

17. Henderson-King D H-KE. Acceptance of cosmetic surgery: scale development and validation. Body Image. 2005;2:137-49.

18. Menzel JE, Sperry SL, Small B, Thompson JK, Sarwer DB, Cash TF. Internalization of Appearance Ideals and Cosmetic Surgery Attitudes: A Test of the Tripartite Influence Model of Body Image. Sex Roles. 2011;65:469-77. 